Gut, 1989, 30, 510-514

\title{
Prevention of postischaemic lipid peroxidation and liver cell injury by iron chelation
}

\author{
R OMAR, I NOMIKOS, G PICCORELLI, J SAVINO, AND N AGARWAL \\ From the Departments of Pathology and Surgery, New York Medical College, Valhalla, NY, USA
}

SUMMARY Liver ischaemia was induced by cross clamping the hilar pedicle for 30 minutes in groups of rats with or without treatment with the iron chelating agent desferrioxamine (deferoxamine, DFR). The groups included eight animals each and were divided into the following treatment categories: control; ischaemia alone; ischaemia with subsequent reperfusion; ischaemia preceded by DFR, $60 \mathrm{mg} / \mathrm{kg}$ body weight; and reperfusion preceded by 20,40 , or $60 \mathrm{mg} / \mathrm{kg} \mathrm{DFR}$. The drug was given intravenously five minutes before either ischaemia or reperfusion. Malondialdehyde (MDA), a product of lipid peroxidation, and histopathological changes of liver tissue samples were used as indicators of hepatocellular injury. Lipid peroxidation (MDA concentration in $\mu \mathrm{mol} / \mathrm{kg}$ liver tissue) was highest $(4 \cdot 76(1 \cdot 19))$ after ischaemia without reperfusion and less pronounced $(2 \cdot 87$ $(0 \cdot 34))$ after reperfusion. Both concentrations, however, were significantly $(p<0 \cdot 05)$ higher than basal (control) values $(1 \cdot 78(0 \cdot 27))$. At $60 \mathrm{mg} / \mathrm{kg}$ body weight, DFR treatment reduced MDA to basal or even lower concentrations in both situations $(1.98(0 \cdot 08)$ and $1 \cdot 26(0 \cdot 06)$, respectively) with a corresponding improvement in liver histopathology. Lower DFR doses were less protective. The data suggest that liver ischaemia is associated with free radical initiated, and apparently iron catalysed lipid peroxidation, which can be significantly decreased by iron chelation.

The harmful effects of complete interruption of blood flow to an organ has long been a topic of intense interest. Complete interruption of blood flow to the liver is often necessary during surgical intervention for trauma or when extensive resection of a tumour is performed. ${ }^{\prime}$ With the recent development of liver transplantation, the effects of temporary ischaemia on restoration of liver function are of even greater importance. Under these conditions, the harmful consequences of liver ischaemia and subsequent reflow on liver function are often related to injury at the cellular and subcellular level (membrane integrity, mitochondrial function, protein synthesis, DNA, etc)..$^{2-\infty}$

Damage to cell and organelle membranes is probably the critical lesion that precedes irreversible cell injury. ${ }^{3}$ This has been largely attributed to peroxida-

Address for correspondence: R Omar, MD, PhD, Department of Pathology. Basic Science Building. New York Medical College, Valhalla, NY. 10595. USA.

Accepted for publication 30 September 1988 tion of membrane lipids which can be initiated by oxygen free radical species such as the superoxide anion $\left(\mathrm{O}_{\overline{2}}^{\overline{1}}\right)$ and some of its active derivatives. ${ }^{-10}$ Superoxide is generated during normal respiratory metabolism but is rapidly metabolised by the enzyme superoxide dismutase, which converts it to hydrogen peroxide $\left(\mathrm{H}_{2} \mathrm{O}_{2}\right)$ that is in turn metabolised to water by catalase and glutathione peroxidase. "Some low molecular weight substances, such as vitamin E and ascorbic acid, can also serve as free radical scavengers. Free radicals beyond the capacity of cellular scavenging mechanisms can interact with many subcellular structures, such as membrane lipids, to form lipid peroxides and thus disrupt the integrity of the affected membranes. ${ }^{12}$

Lipid peroxidation takes place in a chain reaction through which a polyunsaturated fatty acid (PUFA) is oxidised to produce several intermediate lipidbased free radicals that in turn react with other PUFAs, thus propagating the process and possibly extending the damage to sites and dimensions beyond the initial insult. ${ }^{12}{ }^{1.3}$ Initiation and propaga- 
tion of lipid peroxidation takes place more favourably in the presence of a transitional metal catalyst such as iron, which is quite ubiquitous in mammalian tissues. ${ }^{14}$ In addition, $\mathrm{O}_{\dot{2}}^{-}$is capable of releasing iron directly from ferritin (by reduction of ferric to ferrous form $).{ }^{15}$ Ferrous iron $\left(\mathrm{Fe}^{++}\right)$can donate one electron to intermediate byproducts of lipid peroxidation, thus creating additional free radicals.'2 Similarly, low molecular weight chelates of iron, such as ADP-Fe" ${ }^{+1}$, can undergo reactions with oxygen to generate active oxidation species that directly initiate lipid peroxidation in PUFAs. ${ }^{13}$

Available evidence indicates that free radical mediated lipid peroxidation takes place not only during reperfusion, when the sudden oxygen flux produces significant amounts of free radicals, but also during hypoxia itself despite the low oxygen tension. ${ }^{\text {th }}$ During hypoxia, cellular processes take place in a 'reducing' environment with anaerobic metabolism and low adenosine triphosphate (ATP) production." Under these conditions, there is an accumulation of hypoxanthine and increase in intracellular calcium with associated conversion of xanthine dehydrogenase to xanthine oxidase. The latter acts on xanthine and hypoxanthine, even under minimal oxygen tension, to produce superoxide radicals. ${ }^{16}$ Under hypoxic conditions, other substances like coenzyme Q, and even ascorbic acid, undergo autooxidation from their reduced forms to produce radical species capable of initiating lipid peroxidation. ${ }^{17}$ Hypoxia is also associated with a rapid release of iron from ferritin, ${ }^{18}$ which assists in propagating the process of lipid peroxidation even further.

Most recent studies that have been concerned with the role of lipid peroxidation in postischaemic injury have focused mainly on the role of reperfusion in its pathogenesis. ${ }^{15016}$ The purpose of this study was to examine the extent of such injury in rat liver tissue after ischaemia alone or with subsequent reperfusion, and to explore the effect of iron chelation on its prevention or amelioration.

\section{Methods}

EXPERIMENTAL ANIMALS

Young male, Sprague-Dawley, rats each weighing approximately $250 \mathrm{~g}$, were used after about one week of acclimatisation, during which they were provided with food and water ad libitum. Animals were divided into five experimental groups: group I. Animals killed after minimal or no stress. No surgery was performed on these animals before death. Data obtained from this group served as a base line; group II. Animals which were subjected to anaesthesia, laparotomy and 30 minutes of liver ischaemia after which they were immediately killed (without reperfusion). They were intravenously injected with $0.5 \mathrm{ml}$ normal saline five minutes before the induction of ischaemia; group III. Reperfusion was allowed in these animals after 30 minutes of liver ischaemia. They were intravenously injected with $0.5 \mathrm{ml}$ normal saline, five minutes before reperfusion; group IV. Same as in group II but instead of saline, animals were injected with $0.5 \mathrm{ml}$ solution containing DFR (Ciba-Geigy, Summit, NJ, USA), $60 \mathrm{mg} / \mathrm{kg}$ body weight; group V. Same as in III but instead of saline, animals were injected with DFR, $20 \mathrm{mg} / \mathrm{kg}$ (subgroup $\mathrm{Va}$ ), $40 \mathrm{mg} / \mathrm{kg}$ (subgroup $\mathrm{Vb}$ ), or $60 \mathrm{mg} / \mathrm{kg}$ (subgroup $\mathrm{Vc})$.

Eight animals were used in each of groups I, II, and IV. In these groups all animals were killed by decapitation at the end of the procedure as outlined above. There livers were immediately removed, placed on ice, dissected and representative samples used for assessing tissue injury by means of measuring lipid peroxidation and histopathological examination. For groups III and V, 16 animals were used in each group or subgroup: eight were killed two hours after the procedure and their liver tissue used for determining lipid peroxidation while the remaining eight were allowed to recover from surgery. These were killed 24 hours later and their livers used for histopathological examination. This delay was necessary since it usually takes more than eight to 12 hours before irreversible cell injury (necrosis) becomes detectable by light microscopy. Obviously, such a waiting period is incompatible with the experimental design of groups I, II, and IV where only ischaemia (without reperfusion) was intended. Hence, the same animal in each of these groups was used for both, the histological and the biochemical studies immediately after the ischaemic period while duplicate animals were used in the reperfused groups.

\section{LIVER ISCHAEMIA}

Rats were anaesthetised with an intraperitoneal injection of pentobarbital sodium, $40 \mathrm{mg} / \mathrm{kg}$ body weight. This was followed by 80 units of heparin intravenously. Liver ischaemia was induced by cross clamping of the entire hilar pedicle (hepatic artery, portal vein and common bile duct). In animals where reperfusion was intended, the clamp was released at the end of the ischaemic period. All intravenous injections were done via the right femoral vein.

\section{LIGHT MICROSCOPY}

Slices of liver tissue were fixed in $10 \%$ buffered formalin, routinely embedded in paraffin and $5 \mu$ sections stained with haematoxylin and eosin (HE) and Periodic Acid-Schiff (PAS) methods. Slides were examined by light microscopy and the extent of 
hepatocellular pathology evaluated. This was done in a double blind fashion using coded slides.

\section{LIPID PEROXIDATION}

Malondialdehyde (MDA) is the major product of peroxidation of polyunsaturated fatty acids and hence, it has been widely used as an index of free radical mediated lipid peroxidation. ${ }^{13}$ We measured MDA concentrations in liver tissue homogenates using the method described by Slater and Sawyer. ${ }^{19}$ Two grams of liver tissue were cut into small fragments, washed with normal saline and homogenised in $1 \mathrm{ml}$ distilled water while on ice. After homogenisation, $4 \mathrm{ml} \mathrm{5 \%}$ trichloroacetic acid were added and the homogenate thoroughly mixed. This was followed by centrifugation at $2000 \mathrm{~g}$ for 15 minutes $1.5 \mathrm{ml}$ of the supernatant was mixed with $1.5 \mathrm{ml}$ of $0.67 \%$ thiobarbituric acid and the mixture heated at $100^{\circ} \mathrm{C}$ for 30 minutes. The solutions were then cooled on ice for five minutes and the absorbance of the individual samples determined at $532 \mathrm{~nm}$ wavelength. The concentration of MDA (in $\mu \mathrm{mol} / \mathrm{kg}$ liver tissue) was calculated using an extinction coefficient of $153000 /$ $\mathrm{Mol} / \mathrm{cm}$.

\section{STATISTICAL ANALYSIS}

The Student's $t$ test and one-way analysis of variance were used to determine the level of significance for observed differences among the various groups.

\section{Results}

The results of MDA determinations are presented in Table 1. Liver ischaemia (group II) was associated with a significant increase in MDA concentration over baseline (group I). Ischaemia followed by reperfusion (group III) was also associated with an MDA level that is still significantly higher than in group I but much lower than in group II. Treatment with DFR $(60 \mathrm{mg} / \mathrm{kg})$, five minutes before the induction of ischaemia resulted in a significant reduction of MDA level (group IV). When ischaemia was followed by DFR treatment and reperfusion (group $\mathrm{V})$, MDA concentrations returned to near basal values (subgroups $\mathrm{Va}$ and $\mathrm{Vb}$ ) or even lower (subgroup $\mathrm{Vc})$.

The histopathological changes observed in representative sections from liver of animals killed 24 hours after ischaemia were assigned histological scores (HS) based on the extent of hepatocellular injury as follow: HS 0-1: No changes or reactive changes only (swelling, congestion, single cell dropout and glycogen depletion). HS 2: Mild injury; one or more minute foci of necrosis, the largest involving approximately less than $1 \%$ of examined sectional area of the lobule. HS 3: Moderate; as in 2 but the necrotic foci are approximately $1-5 \%$ of the lobule. HS 4: Severe; as above but more than $5 \%$.

Histological scores for the eight animals from which histological sections were studied in each group or subgroup are presented in Table 2.

\section{Discussion}

Our data show that liver ischaemia was associated with an increase in the concentration of MDA, a byproduct of lipid peroxidation. This indicates that free radical mediated peroxidation of membrane

Table 1 Malondialdehyde concentrations ( $\mu$ mol/kg liver tissue) of individual animals from the various experimental groups. Significant difference $(p<0.05)$ is indicated by: *, from I; + , from II; $\neq$, from III

\begin{tabular}{|c|c|c|c|c|c|c|c|}
\hline \multirow[b]{4}{*}{ Animals } & \multicolumn{7}{|c|}{ Experimental groups } \\
\hline & \multicolumn{3}{|c|}{ Without DFR } & \multicolumn{4}{|c|}{ With DFR } \\
\hline & \multirow[b]{2}{*}{$\begin{array}{c}I \\
\text { Control }\end{array}$} & \multirow[b]{2}{*}{$\begin{array}{c}\text { II } \\
\text { Ischaemia }\end{array}$} & \multirow[b]{2}{*}{\begin{tabular}{l}
\multicolumn{1}{c}{ III } \\
Ischaemia + \\
reperf.
\end{tabular}} & \multirow[b]{2}{*}{$\begin{array}{l}I V \\
60 \mathrm{mg} / \mathrm{kg}+ \\
\text { ischaemia }\end{array}$} & \multicolumn{3}{|c|}{$\begin{array}{c}V \\
\text { Ischaemia }+D F R+\text { reperfusion }\end{array}$} \\
\hline & & & & & $\begin{array}{l}\mathrm{Va} \\
20 \mathrm{mg} / \mathrm{kg}\end{array}$ & $\begin{array}{l}V b \\
40 \mathrm{mg} / \mathrm{kg}\end{array}$ & $\begin{array}{l}V c \\
60 \mathrm{mg} / \mathrm{kg}\end{array}$ \\
\hline 1 & 2.76 & $8 \cdot 62$ & $3 \cdot 51$ & $2 \cdot 07$ & $2 \cdot 02$ & 1.72 & $1 \cdot 11$ \\
\hline 2 & 1.02 & 1.01 & $2 \cdot 00$ & $2 \cdot 20$ & $2 \cdot 23$ & $3 \cdot 13$ & $1 \cdot 15$ \\
\hline 3 & 1.29 & $5 \cdot 27$ & $2 \cdot 52$ & 1.72 & $1 \cdot 36$ & 1.58 & 1.44 \\
\hline 4 & 3.07 & $8 \cdot 18$ & $2 \cdot 54$ & $2 \cdot 01$ & $2 \cdot 15$ & 1.55 & 1.03 \\
\hline 5 & 1.47 & $4 \cdot 20$ & $3 \cdot 42$ & 1.76 & 1.51 & $2 \cdot 42$ & $1 \cdot 35$ \\
\hline 6 & $2 \cdot 08$ & $1 \cdot 11$ & 4.04 & $2 \cdot 31$ & $2 \cdot 21$ & $2 \cdot 96$ & 1.41 \\
\hline 7 & $1 \cdot 20$ & $8 \cdot 39$ & 3.73 & 1.65 & $2 \cdot 10$ & $1 \cdot 17$ & $1 \cdot 50$ \\
\hline 8 & $1 \cdot 35$ & $1 \cdot 30$ & $1 \cdot 20$ & $2 \cdot 12$ & $1 \cdot 30$ & $2 \cdot 11$ & 1.09 \\
\hline Mean & 1.78 & $4 \cdot 76^{*}$ & $2 \cdot 87^{*}$ & $1.98+\ddagger$ & $1.86 \dagger \ddagger$ & $2 \cdot 08 \dagger$ & $1 \cdot 26 \dagger \ddagger$ \\
\hline $\mathrm{SE}$ & 0.27 & $1 \cdot 19$ & 0.34 & 0.08 & $0 \cdot 14$ & 0.25 & 0.06 \\
\hline
\end{tabular}


Table 2 Number of animals in each group assigned a particular score of liver pathology: (0-1, none or reactive changes; 2, mild; 3, moderate; 4, severe injury. Experimental setting for each group is as in table 1.

\begin{tabular}{lllll}
\hline & \multicolumn{2}{l}{ Histological score } & \\
\cline { 2 - 5 } Group & $0-I$ & 2 & 3 & 4 \\
\hline I & $8^{*}$ & & & \\
II & $8^{*}$ & 1 & 2 & 5 \\
III & $8^{*}$ & 3 & 1 & 1 \\
IV & 3 & 2 & 1 & 1 \\
Va & 4 & 2 & 2 & \\
Vb & 4 & 2 & & \\
Vc & & & & \\
\hline
\end{tabular}

*No changes detectable by light microscopy were expected as these animals were killed immediately after the procedure.

lipids might have been a key pathogenetic mechanism in the chain of events that eventually lead to hepatocellular necrosis which we observed histologically in surviving animals. Liver reperfusion was expected to promote an even higher degree of lipid peroxidation as a result of the sudden increase in oxygen uptake and free radical generation by liver cells. While this might, indeed, have transiently been the case, our data show that the 'net' lipid peroxidation product (MDA) after reperfusion, although high, was actually lower than that seen after ischaemia alone. The explanation for this seemingly unexpected result probably lies in two phenomena that might have been previously overlooked. First, the absence of blood flow during ischaemia leaves many of the freshly generated free radical species in place, thus allowing them to react with other molecules and enter in free radical producing chain reactions. Second, by halting the blood flow, liver tissue is deprived from numerous antioxidants or free radical scavengers that are ordinarily brought in by the circulating blood. These two phenomena are reversed upon reperfusion with a net result, apparently, favouring a modest reduction in the cumulative amount of local free radicals.

In both situations (ischaemia alone and ischaemia with subsequent reperfusion), however, it appears that iron is a key catalyst so that its neutralisation was associated with a significant reduction in lipid peroxidation. This was accomplished by using the iron chelating agent deferoxamine. A single dose of 60 $\mathrm{mg} / \mathrm{kg}$ body weight, given either before the induction of ischaemia or before reperfusion, was sufficient to prevent most, if not all of the harmful lipid peroxidation. This was evident not only by comparing the concentrations of MDA in liver homogenates, but also by histopathological examination of liver tissue from surviving animals. In about $80 \%$ of these animals, evidence of only minimal to moderate hepatocellular injury was found while about $60 \%$ of the nontreated animals showed evidence of severe injury. At this dose $(60 \mathrm{mg} / \mathrm{kg})$, DFR was relatively protective even against a more extended ischaemia. In an unpublished study, only three of 21 animals $(14.3 \%)$ which we subjected to 45 minutes of liver ischaemia survived. Pretreatment of a similar group of animals with DFR resulted in eight $(38.8 \%)$ survivals. Deferoxamine in doses higher than $60 \mathrm{mg} /$ $\mathrm{kg}$ did not provide a significant additional protection. Lower doses (40 and $20 \mathrm{mg} / \mathrm{kg}$ ), however, while relatively beneficial were less protective.

Measuring MDA concentrations in a variety of tissues has been widely used to evaluate the extent of lipid peroxidation and hence, free radical injury. Evidence of the latter in rat liver after surgically induced ischaemia was documented by Marubayashi et al, ${ }^{70}$ who found a decrease in $\alpha$-tocopherol and glutathione (intracellular free radical scavengers) and a slight increase in MDA concentrations. All of these changes, however, became more significant after restoration of blood flow. The discrepancy between their findings and ours may be because of the differences in experimental protocol as they added a 'portofemoral shunt' to the vessel clamping procedure. These authors and others' used low molecular weight free radical scavengers to ameliorate postischaemic liver injury with variable success. In other experiments, high concentrations of MDA were found in myocardial tissue which had been reperfused after prolonged regional ischaemia. ${ }^{21}$ Reduction in MDA production was achieved by administering SOD during reperfusion. Increased MDA in ischaemic myocardium was associated with an increase in low molecular weight chelate forms of iron ${ }^{22}$ which supports the proposed role of iron in catalysing lipid peroxidation during ischaemia/reperfusion. Similar results were observed in experiments with brain ischaemia and reperfusion in animals. ${ }^{33}$ An increase in MDA concentrations in these experiments was prevented, like in our studies, by treatment with DFR.

Among several known metal chelators, DFR has proved most effective in inhibiting iron mediated free radical production. It is a specific chelator of $\mathrm{Fe}^{++}$ and can be injected into humans and experimental animals where it easily penetrates the blood brain and cell membrane barriers. ${ }^{33-25}$ Iron bound in the DFR complex is chemically inert and iron dependent lipid peroxidation cannot occur in the presence of stoichiometrically adequate amounts of DFR. ${ }^{24}$

Deferoxamine and other drugs, such as the xanthine oxidase inhibitor allopurinol, ${ }^{2 h}$ which can prevent the formation of free radical species or their propagation, in the first place, may prove far more 
beneficial than free radical scavengers which act upon already formed free radicals.

With the continuing necessity of intraoperative liver ischaemia for various surgical manipulations, experimental models similar to the one herein described have obvious practical implications, although more in depth studies are still needed.

\section{References}

1 Hasselgren PO. Prevention and treatment of ischemia of the liver. Surg Gynecol Obstet 1987; 164: 187-96.

2 Clemens MG, McDonagh PF, Chaudry IH, Baue AE. Hepatic microcirculatory failure after ischemia and reperfusion: improvement with ATP- $\mathrm{MgCl}_{2}$ treatment. Am J Physiol 1985; 248: 804-81.

3 Farber JL, Chien KR. Mittnach S. The pathogenesis of irreversible cell injury in ischemia. Am J Pathol 1981; 102: $271-81$.

4 Fornander J, Bergmark J, Jagenburg R, Hasselgren PO. Evaluation of an in vitro method for the study of hepatic protein synthesis in liver ischaemia. Eur Surg Res 1985; 17: $91-100$

5 Morehouse LA. Thomas CE, Aust SD. Superoxide generation by NADPH-cytochrome $\mathrm{P}-450$ reductase: the effect of iron chelators and the role of superoxide in microsomal lipid peroxidation. Arch Biochem Biophys 1984; 232: 366-77.

6 Marubayashi S, Takenara M, Dohi K, Ezaki H, Kawasaki T. Adenine nucleotide metabolism during hepatic ischemia and subsequent blood reflow periods and its relation to organ viability. Transplantation 1980; 30: 294-6.

7 Marubayashi S, Dohi K, Ezaki H, Hayashi K, Kawasaki $T$. Preservation of ischemic rat liver mitochondrial functions and liver viability with $\mathrm{CoQ}_{10}$. Surgery 1982; 91: $631-7$.

8 Aust SD, Svigen BA. The role of iron in enzymatic lipid peroxidation. In: Pryor WA, ed. Free radicals in biology. Vol V. New York: Academic Press, 1982: 1-28.

9 Babbs CF. Role of iron ions in the genesis of reperfusion injury following successful cardiopulmonary resuscitation: preliminary data and a biochemical hypothesis. Ann Emerg Med 1983; 14: 777-83.

10 Thiel H. Liver hemodynamics and portocaval shunt. Surg Gynecol Obstet 1980; 150: 887-92.

11 Omar RA, Yano S, Kikkawa Y. Antioxidant enzymes and survival of normal and SV40-transformed mouse embryo cells after hyperthermia. Cancer Res 1987; 47: $3473-6$.
12 Mead JF. Free radical mechanisms of lipid damage and consequences for cellular membranes. In: Pryor WA, ed. Free radicals in biology. Vol V. New York: Academic Press, 1976: 51-68.

13 Slater TF. Overview of methods used for detecting lipid peroxidation. In: Packer L, ed. Methods in enzymology. Vol 105. New York: Academic Press, 1984: 283-92.

14 Perry HM. Tipton IH, Schroeder HA, Cook MJ. Variability in the metal content of human organs. $J$ Lab Clin Med 1962; 60: 24.5-53.

15 Thomas CE, Morehouse LA, Aust SD. Ferritin and superoxide dependent lipid peroxidation. $J$ Biol Chem 1985; 60: $3275-80$.

16 White BC, Krause GS, Aust SD, Eyster GE. Postischemic tissue injury by iron-mediated free radical lipid peroxidation. Ann Emerg Med 1985; 14: 804-9.

17 Demopoulos H, Flamm E, Selgman M, Pietronigro D. Oxygen free radicals in central nervous system ischemia and trauma. In: Autor AP, ed. Pathology of oxygen. New York: Academic Press, 1982: 127-55.

18 Sirivesh S, Frieden E, Osaki S. The release of iron from horse spleen by reduced flacins. Biochem J 1974; 143: $311-5$.

19 Slater T. Sawyer B. The stimulatory effect of carbon tetrachloride and other halogenoalkanes on peroxidative reactions in rat liver fractions in vitro. Biochem $J$ 1971: 123: 805-14.

20 Marubayashi S, Dohi K, Ochi K, Kawasaki T. Role of free radicals in ischemic rat liver cell injury and prevention of damage by tocopherol administration. Surgery 1986; 99: 184-91.

21 Jolly SR, Kane WJ, Bailic MB, Abrams GD, Lucchesi $B R$. Canine myocardial reperfusion injury. Its reduction by the combined administration of superoxide dismutase and catalase. Circ Res 1984; 54: 277-84.

22 Holt S, Gunderson M. Joyce K, et al. Myocardial tissue iron delocalization and evidence for lipid peroxidation after two hours of ischemia. Ann Emerg Med 1986; 15: 1155-9.

23 Gutteridge JM, Richmond R, Haliwel B. Inhibition of the iron-catalyzed formation of hydroxyl radicals from superoxide and lipid peroxidation by desferrioxamine. Biochem J 1979; 184: 469-72.

24 Haliwel B, Gutteridge J. Role of iron in oxygen radical reactions. In: Packer L, ed. Methods in enzymology. Vol 105. New York: Academic Press, 1984: 47-56.

25 Keberle $\mathrm{H}$. The biochemistry of desferoxamine and its relation to iron metabolism. Ann NY Acad Sci 1974; 119: $758-68$.

26 Nordstrom G, Seeman T, Hasselgren PO. Beneficial effect of allopurinol in liver ischemia. Surgery 1985; 97: 679-84. 